\title{
APPROPRIATE WRITING ASSESSMENT, HOW DO WE DO IT PROPERLY?
}

\author{
Martin Surya Putra \\ State Polytechnics of Samarinda \\ mrtputra@yahoo.com
}

\begin{abstract}
This paper describes the assessment upon the 3rd semester Business Administration students' writing work of State Polytechnics Samarinda. Results show that there are weaknesses done by the English lecturer of this Polytechnics in evaluating his students' work: 1) Instructions given to his students were not clear for examples: how many pages or how many words they had to write, resulting in a very short paragraphs, a very long paragraph written by students, 2) criteria of assessment were not clear, reflected by his own judgment and interpretation in form of words like: good, fair, excellent; 3) Students were not given a feedback on what they had written in form of the first draft and neither were they told to rewrite the first draft for final product.
\end{abstract}

Keywords: assessment, paragraph, writing.

Technological advancement has also had a considerable impact on education. The invention of internet and cellular phones through which people can communicate through programs called chatting and short message services (SMS) has shifted other means of communication such as the handy-held 2-meter-band radios used by many people in late 1980s. These radios have been considered old-fashioned nowadays, although they are still effective and widely used by military, police and emergency services as the cheapest means of communication.

The impact of this technology, of course, requires anyone to be able to use their ability to write things down. They need to use their productive skill to express their feeling, words of mouth in written forms to get the meaning across. And as a result, a lot of verbal forms can be found in written. The trend then has also been seen by the industrial world as an opportunity to promote their products in such a way to get profit from what they advertise. A domestic cigarette and kreteks company known as Sampoerna Mild is reputable to use such advertisements on giant advertising boards everywhere within the archipelago. This could also be an example how effective writing can attract people image towards something to be remembered and stored in their memory to win the market.

Basic considerations in writing assessment is obviously to do with language ability as described by Bachman and Palmer (1996) that the main purposes in language tests is to make inferences about language ability, and the secondary purpose is to make decisions based on those inferences, that is, since we cannot directly observe a person's language ability, we use his or her responses to test items as data from which we make inferences about the ability that underlies the test performance. These inferences are then used as data for making a variety of decisions at an individual, classroom, or program level, tests".

With the intention of being able to communicate in L2, the teaching of writing should also be oriented towards communicative 
approach, i.e. directing students to be able to use functional and practical language for their day-to-day communication, and so is the evaluation of the skill taught to them such as writing. Assessment on the students' writing should reflect their productive communication skill using the English language skill.

Unfortunately, however, the assessment used in most universities in Indonesia has not reflected the students' real ability in writing. Standardized international TOEFL test is preferred to the writing test itself with an argument that TOEFL can reflect the overall English language proficiency than a single test like writing. The choice on TOEFL would probably have been on its compatibility and world-wide availability in the market. One thing that lecturers and teachers have forgotten in giving the TOEFL to their students is that the basic purpose of the TOEFL is to measure one's academic English proficiency. This means that the test is more specific than knowing students' proficiency in general.

Most TOEFL used in most language laboratories at universities is the old-fashioned paper and pencil one. The fact that this type of test can be found a lot in the market has motivated most language laboratories at universities to use this type of test for their students. Another consideration is the assessment factor that the assessor does not have to think and spend his time correcting productive skills such as speaking and real composition writing as the test does not any. He just simply put the correct hollow multiple-choice answer sheet onto the sheet to be corrected to correct students' answer and they get the score. Easiness such as this has made this test more popular than most conventional tests, which require an assessor to spend his time.

It is about time that teachers and lecturers in Indonesia change their current attitude that relies only on easiness and comfort. It is not going to be easy, or course, to shift from the current habit into something considered unusual, but good quality education appears to provide no alternative than changes in attitude.

It is, therefore, important that English teachers and lecturers have to keep up with the development particularly in the field of language teaching assessment if the quality of language teaching in Indonesia is to be advanced. Kantor in personal communication (March 2000) cited in Weigle (2002; 15) describes the current International or Internetbased TOEFL requires that all raters must pass a calibration test at the beginning of each scoring day before they begin scoring. Scoring Leaders can also observe rater performance on 'monitor papers', pre-scored papers that comingled with the responses that are being scored.

It would obviously be a good idea if English language teachers and lecturers be trained in such assessment regarding the productive skills of the English language proficiency and be given certificates on such skill to able to be implemented for their institutions. The role of current certification not only does it require teachers and lecturers to be competent in their field of teaching competency, but also in judging a matter that does not look significant on the surface level, but it does bring a significant influence over students' overall achievement.

\section{METHOD}

The research was focused on the Polytechnics students studying in the Business Administration Department of State Polytechnics Samarinda, East Kalimantan who obtain more writing work than those of other Departments within the college. Unlike the engineering department that is given two hours a week of tutorial, the Business Administration are given 6 hours a week of tutorial for English intensively right from semester 1 to semester 6. A figure of four hours a week is based on the Polytechnics curriculum adopted from Australia for the commerce departments (business administration and accounting) for Polytechnics education in Indonesia. While the engineering departments adopted 
their curriculum from Switzerland.

As a qualitative research, the way the English teachers teach in the Business Administration Department and how the students' writing works are evaluated were observed. Unlike speaking, the aim of teaching writing is obviously to enable students at college level to produce good writing in particular and to have good English proficiency in general as expected by Polytechnics in its short and long-term development plan.

\section{FINDINGS}

The teaching of writing in the Business Administration Department revealed that it has been very good and practical. The English teacher responsible for the course given is not oriented to the theoretical basis. Students are exposed to quite a lot of language usage and they have to explore day-to-day practical examples to strengthen their four language skills. The teaching of writing in particular has always been integrated with the other language skills such as listening, speaking and reading meaning that writing is not taught in isolation. Weigle in Assessing writing $(2002 ; 15)$ also has a similar view toward the nature of teaching writing that both writing and speaking skills have a close relationship that play an important role in language testing because they draw on many of the same linguistic resources and also rely on distinctly different mental processes.

His view was based on Grabe and Kaplan (1996) who pointed out that linguists and education researchers have historically held contradictory positions about the relationship between writing and speaking: traditional linguistic inquiry has held that speech is primary and written language is merely a reflection of spoken language, while educational research has taken the stance that the written form of the language is more 'correct' and therefore should be more highly valued than oral language. However, in recent years a consensus has been emerging to reconcile these two positions: neither oral nor written language is inherently superior to the other, but oral and written texts do very across a number of dimensions, including (but not limited to) textual features, socio-cultural norms and patterns of use, and the cognitive processes involved in text production and comprehension.

The students' writing works show integration between speaking and writing skills. Having completed with speaking task based on reading, students followed on with writing their own narration as the dialog they did with their partners in the classroom asking and answering activity. But this time as they wrote, the activity was slightly different from the previous one because they had to write the spoken language form into the written one with a different style. This reflects an example of real-life situation, where they would be required to do a possible similar activity later at work.

\section{DISCUSSION}

The writing assessment done by the English teacher, however, shows a few weaknesses. Students were not given clear instructions on what they had to do regarding their writing task. The instruction they were given was they had to write a writing task describing people without a limitation such as: how many paragraphs, how many pages or how many words they had to write. This unclear instruction resulted in students ending up collecting their writing task in a very short paragraph, a few sentences, a few paragraphs long. This made the lecturer teaching this subject difficult to assess his students' work. He could not have given an objective assessment towards his students' assessment.

Weir in "Understanding \& Developing Language Tests" (1993: 131) suggests that as with testing the other language skills, it is useful to start by considering a framework of the features we might wish to take into account in designing writing tests. Further, he 
provided two tables for this framework as follows:

\section{Table 1: Summary Checklist of performance conditions (writing)}

Purpose: realistic

Text type required: form, letter, message, note, notice, postcard, report, speech, set of directions/ instructions, article, written assignment, summaries, memo, poem, story, etc.

Demands which construction of the text(s) places on the writer vis a vis:

Organizational: grammar, cohesion, rhetorical organization.

Propositional:

lexical range, common core, technical, sub-technical.

Type of information (abstract/ concrete)

Cognitive demands

\section{Illocutionary:}

function range (within texts)

Range of tasks/ text types required in test.

\section{Topic:}

level of specificity. Personal/ non-personal. Relationship between content of output text and candidates' background knowledge, information given or invented; response to information provided or self-initiated.

Channel or presentation: plus or minus visuals; layout; typeface.

Addressee: known/ unknown, relationship between writer and audience, e.g. equal to equal, expert to layperson; knowledge of audience's attitudes, beliefs, and expectations.
Setting where it is written - examination hall or at home.

Time available: speed at which processing must take place, length of time available to write, normal time constraints; whether is an exam or hand-in assignment, and the number of revisions/ drafts allowed (process element).

Size of output, length of text.

Amount of support given: plus or minus dictionary. Clarity of rubrics: L1/TL.

Method factor/ response mode: familiarity with task type and other test environment features. Length of prompt. Integration with reading task: single or multi-source. Verbal and/or non-verbal input.

Stated or unstated criteria or assessment: (these relate to level but affect conditions to the extent they are known to the candidates or not).

Further, he provides a table containing a checklist of operation for writing task. The intention of this table is to help lecturers/ teachers in the classroom to follow up with the framework they have chosen. In other words, it could be a guideline for them.

Table 2: Summary Checklist of operations (writing)

Interactional in social and service texts (adapted and developed from RSA/ UCLES list. See Weir 1990, Appendix III: 149-70):

Expressing: thanks, requirements, opinion, attitude, confirmation, apology, wants/ needs/ lack, ideas, information, complaints, reasons, justifications, etc 
Eleciting information, directions, service, clarification, help, permission, etc.

Directing: ordering, instructing, persuading, advising, warning.

Informational in academic texts (acknowledgement to Keith Johnson for early version of this list):

Describing phenomena and ideas which might involve:

Definition

Classification

Identification

Comparison and contrast

Exemplification

Summary

Describing process which might involve:

Purpose

Describing means, results, process,

change of state

Sequential description

Instructions

Summary

Argumentation which might involve:

Stating a proposition

Stating assumptions

Induction

Deduction

Substantiation

Concession

Summary

Generalisation

Speculation/ comment/ evaluation

Microlinguistic level:

Handwriting

Handing: grammar, vocabulary, cohesive devices, discourse markers.

In terms of time, writing tasks given to students should be allocated for length of time they have to complete their tasks as Weir
(1993: 135) describes that apart from examination essays, in the real world, writing tasks would not timed at all that students would be allowed maximum opportunity and access to resources for demonstrating their writing abilities. For the task given, students were given a week to bring home with them as a homework. This had enabled them to explore the task closed to real situations.

Weir is supported by Harmer in "How to teach writing" (1996: 31): Partly because of the nature of the writing process and also because of the need for accuracy in writing, the mental processes that a student goes through when writing differ significantly from the way they approach discussion or other kinds of spoken communication. This is just as true for single-sentence writing as it is with single paragraphs or extended texts. Further, he comments that when writing, students frequently have more time to think than they do in oral activities. They can go through what they know in their minds, and even consult dictionaries, grammar books, or other reference material to help them. Writing encourages students to focus on accurate language use, and, because they think as they write, it may well provoke language development as they resolve problems which the writing puts into their minds.

The difference between homework and tasks conducted in the classroom should be converted into a time-line, as this is related to the reliability of the writing test. Weir (1993: 135) further says that the texts we get candidates to produce obviously have to $b$ long enough for them to be marked reliably. If we want to establish whether a student can organize a written product into coherent whole, length is obviously a key factor. Jacobs et al $(1981 ; 19)$ in their research on the Michigan Composition Test, however, found that a time allowance of thirty minutes probably gave most students enough time to produce an adequate sample of their writing ability. 
Table 3: Summary Checklist of quality of output: assessment criteria (writing)

Relevance and adequacy of content

Organization

Cohesion

Adequacy of vocabulary for purpose

Grammar

Punctuation

Spelling

Appropriateness of language to context, function and intention and appropriateness of layout.
Last week

Yesterday one of my asked me to help

Recently

5. Oral cloze - combining dictation with selected cloze using high-frequency deletion. Difficult content words or grammar not covered yet can be intact.

\section{Assessments on Writing}

O'Malley and Pierce (1995: 142),. The scoring of authentic assessments should always be defined before the exercises and assessment procedures developed. Three types of rating

\begin{tabular}{l}
\hline Students hear this \\
\hline Have your ever heard of Angel Falls? It's \\
the highest waterfall/ in the world,/deep \\
in the jungles of Venezuela./ Few people/ \\
have ever seen/ Anger falls...
\end{tabular}

\section{Input in the teaching of writing}

In fact, techniques in teaching writing could be enriched by evaluating prewriting as described by Madsen in Techniques in Testing (1983: 102-105):

1. Sentence combining, a common pre-writing task by adding a connective and combining by putting one sentence inside the other. Students can demonstrate their understanding of what various connectives means such as and, moreover, furthermore, but, however, nevertheless, so, consequently, therefore). For examples: He likes ice cream he won't eat any.

2. Sentence expansion - adding words such as adjectives and adverbs.

The ( ) man hurried ( ) to the ( ) horse. The old man hurried out to the frightened horse.

3. Sentence reduction - providing a cue word.

He told us about a man who had a wooden leg (with)

He told us about a man with a wooden leg.

4. Copying - intended to make students aware
Students read this

Have your ever heard of Angel Falls? in___ jungles __ Venezuela. __ people___ ever___ Angel Fallss....

scares generally used in scoring writing are holistic, primary trait and analytic scoring (Cohen 1994; Herman, Aschbacher, and Winters 1992; Perkins 1983). Each of these types has a different purpose and focus in instruction and will provide different types of information to teachers and students.

\section{Holistic Scoring}

This scoring uses a variety of criteria to produce a single score. The specific criteria selected depend on local instructional programs and language arts objectives. The rationale for using a holistic scoring system is that the total quality of written text is more than the sum of its components. Writing is viewed as an integrated whole with the four dimensions: idea development/ organization, fluency/ structure, word choice and mechanics with a score ranging from 1-6.

Holistic Scoring Rubric for Writing Assessment with EL Students the higherst waterfall ___ the world, deep 
Level 6 Conveys meaning clearly and effectively

Presents multi-paragraph organization, with clear introductions, development of ideas, and conclusion.

Shows evidence of smooth transitions.

Uses varied, vivid, precise vocabulary consistently.

Writes with few grammatical/ mechanical errors.

Level 5 Conveys meaning clearly

Presents multi-paragraph organization logically, though some parts may not be fully developed.

Shows some evidence of effective transitions.

Uses varied, vivid vocabulary appropriate for audience and purpose

Writes with some grammatical/ mechanical errors without affecting meaning

Level 4 Expresses ideas coherently most of the time

Develops a logical paragraph.

Writes with a variety of sentence structures with a limited use of transitions.

Chooses vocabulary that is (often) adequate to purpose.

Writes with grammatical/ mechanical errors that seldom diminish communication

Level 3 Attempts to write ideas coherently

Begins to write a paragraph by organizing ideas.

Writes primarily simple sentences

Uses high frequency vocabulary.

Writes with grammatical/ mechanical errors that sometimes diminish communication

Level2 Begins to convey meaning

Writes simple sentences/ phrases

Uses limited or repetitious vocabulary

Spells inventively

Uses little or no mechanics, which often diminishes meaning.

Level 1 Draws pictures to convey meaning

Uses single words, phrases

Copes from a model.

Analytical method attempts to evaluate separately the various components of a piece of writing. Students are given score from 0-100. Another using analytical method is as follows (Madsen: 121):

Mechanics $20 \%$

Vocabulary choice............ $\quad 20 \%$

Grammar and usage .......... $\quad 30 \%$

Organization..................... $30 \%$

Total

$100 \%$

A major problem with analytical approaches is that one never knows just how to weight each error or even each area being analyzed, of which case then, the holistic grading is used. 
Weir (1993: 73) adds that the choice between holistic and analytic scoring depends in part on the purpose of the testing. If diagnostic information is required, then analytic scoring is essential. The choice also depends on the circumstances of scoring. If it is being carried out by a small, well-knit group at s single site, then holistic scoring, which is likely to be more economical of time, may be the most appropriate. But is scoring is being conducted by a heterogeneous, possibly less well trained group or in a number of different places (the British Council ELTS test, for instance, is scored at a large number of test centers), analytic scoring is probably called for. Whichever is used, if high accuracy is sought, multiple scoring is desirable.

\section{CONCLUSION}

It is about time that the productive skill like writing be explored and assessed as it is. So far, most colleges and universities rely on the paper-and-pencil based assessment. Certainly structure and written expression found on the TOEFL cannot reflect the students' real ability in writing. The nature of writing as a productive skill should be assessed appropriately that students are required to produce a piece work on real writing from their own mind realized on a piece of paper either handwritten or computer-typed.

Writing assessment should also be objective reflecting the students' real ability. Therefore, assessment criteria should not be merely in form of statements such as: fair, good, very good and excellent. A teacher or a lecture should be able to judge his students writing ability in form of figures or scores. Thus, holistic or analytic scoring would be appropriate for assessing the students' writing works, if it is intended to improve the students' ability in this productive skill. Writ- ing feedback technique should also be used to give students inputs whether they have reached a progress in their writing skill. Comments or corrections from the teacher and other students are absolutely necessary.

\section{REFERENCES}

Grabe, W., \& Kaplan, R.B. (1996). Theory and Practice of Writing. New York: Longman.

Harmer, J. (2004). How to teach writing. Essex, England. Pearson Education Limited.

Madsen, S.H. (1983). Techniques in Testing. Oxford: Oxford University Press.

O’Malley M.J, \& Pierce V. L. (1995). Authentic Assessment for English Language Learners, USA: AddisonWesley Publishing Company.

Weigle, C. S. (2002). Assessing writing. Cambridge: Language Assessment Series.

Weir, C. (1993). Understanding \& Developing Language Tests, Hertfordshire (United Kingdom): Prentice Hall International. 